\title{
Different Kinds of Matter(s) - Subjectivity, Body, and Ethics in Barad's Materialism
}

By René RosForT

Karen Barad's agential realism offers an original view on nature. This view is based on an "ethico-onto-epistem-ology" in which ethics, ontology, and epistemology are not separate levels of investigation. The consequence of this conflated methodological approach is a theory thatdespite its many merits - disregards crucial aspects of human nature (subjectivity and body) and neglects the concrete problems of ethics.

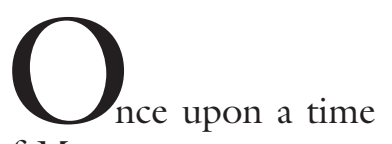

in the fine month of May, many years ago, a princess - and not just any ordinary princess but a remarkably intelligent philosopher-princess - sent a letter to a man renowned for his profound metaphysical insight asking a question that still puzzles philosophers today, more than three centuries later: how is our conscious, rational mind related to the non-conscious matter of our body? When the prominent man at first provides a rather paltry answer about the naturally experienced union of mind and body, the princess promptly comments:

"I admit that it would be easier for me to concede matter and extension to the soul than to concede the capacity to move a body and to be moved by it to an immaterial thing" (Shapiro 2007: 68 [72]).

The year is 1643 , and the correspondents are Princess Elisabeth of Bohemia (16181680) and René Descartes (1596-1650). 
This discussion of the abstruse interaction of the matterless mind and the mindless body marks the beginning of a seven-year long correspondence about central philosophical issues covering metaphysics, mathematics, ethics, and politics.

Besides wanting to draw attention to Elisabeth's penetrating observations, deplorably all too often forgotten, I begin with her question to Descartes because in what follows I want to use some of her observations to articulate some of my concerns regarding Karen Barad's material metaphysics. Elisabeth was among the first philosophers in the dawn of the Western scientific revolution to explicate the problem of how to account for a rational mind in a strictly physical nature, and her acuity is confirmed by the fact that her questions are very much alive at the theoretical core of contemporary philosophy. I shall look at three interconnected issues that remain if not neglected then at least unattended to in Barad's ambitious project, namely, subjectivity, body, and ethics. These have been, and still are, crucial issues for feminist thinking, as well as for philosophy in general. I shall argue that the problems involved in each of these issues point to serious flaws in Barad's ambition to completely revise the traditional ontological and epistemological framework for thinking about physical nature and the existence of human beings in nature. As a consequence of these flaws, I shall venture the conclusion that despite the obvious merits of Barad's work, contemporary feminist theorists need to employ her ideas with caution, if we are to avoid losing sight of disturbingly concrete ethical problems that are still in need of careful analysis.

My argument is developed in four steps. First, I very briefly introduce Barad's theory and its place in the development of contemporary feminism. In the following two sections, I shall look more carefully at the issues of subjectivity and the human body, arguing that they are neglected or at least misconstrued in Barad's work. I conclude with a brief consideration of some ethical issues in contemporary gender studies that may help us to see both the merits and limits of Barad's work.

Obviously, within the restricted limits of this brief article I shall not be able to pay due respect to the breathtaking scope of Barad's knowledge or the details of her analyses; neither do I possess the training or ability to comment on her interpretation of quantum physics. I shall, as mentioned, merely concentrate on what I consider to be serious problems in her conflated methodological approach to (post)human nature.

\section{The Pendulum SWING \\ OF ANTAGONISM AND \\ BARAD'S MATERIALISM}

A brief look at the development of two major, and highly conflicting, currents in our attempt to understand human nature may provide an explanatory background against which we can better assess Barad's materialist theory.

The twentieth century can be read as the scientific century par excellence. In the first decades of the young century, physics and mathematics made extraordinary advances (mathematical set theory, general relativity, quantum physics); in the period from the 1930 s to 1950 s the newly developed molecular biology joined forces with genetics and changed our view of human development. In July 1969 the first human footprint made the moon familiar. The 1970s and 1980s abounded with dazzling computer calculations and surprising, sometimes quite fanciful, evolutionary syntheses purporting to explain human behaviour (first under the name of sociobiology, then as evolutionary psychology). The closing decade experienced colourful insight into the living brain by the combined efforts of the emerging computer sciences and neuroscience, and finally the turbulent century 
was crowned by the first draft of the much advertised mapping of the human genome on June 26, 2000. On the other hand, underneath this amazing and seemingly unflagging scientific progress suspicious voices began to grow louder. The horrible applications of scientific knowledge experienced in the first half of the century (enhanced weaponry, eugenics, allegedly 'scientific' race theories and gender ideologies, and the nuclear bomb) led many intellectuals to question the nature, scope, and limits of the natural sciences and the unfathomable technological advances. This general suspicion crystallized in many theoretical forms that are not easily disentangled from one another (critical theory, second wave feminism, post-colonial studies, deconstruction, postmodernism, science studies, and many more). Whereas the scientific enthusiasts believe in the now rather precarious legend of a steady, unwaveringly objective disclosure of essential features of human nature, the suspicious "legend bashers" (Kitcher 1993 ) emphasize the petrifying and oppressive ideology involved in such a legendbased view of scientific progress. In fact, the suspicious took the idea of a universal human nature to be an artificial construct concocted by overheated propagandists who were stubbornly blind to the complexity of language, insensitive to the significance of culture, and either hopelessly naive or malignantly deaf to the voices of those who suffer under the economically devised schemes of biopolitics. This fight over what it is to be human was simmering throughout a major part of the century, came into full blossom in the last quarter, and is still with us today.

One way to illustrate the tense dynamics of this general antagonism is the literally extreme movement of a pendulum. At the one end of the pendulum swing, we find the scientific enthusiasts advocating a universal or essentialist conception of human nature with a focus on innate, and basically unalterable, differences between women and men, discrete and immutable differences of sexuality, gender dispositions, intelligence and other human features. At the opposite end, we find the suspicious legend bashers who vehemently contest such talk about universal "nature" and about natural, essential features or immutable differences, and instead focus on the plasticity of human characteristics in the form of cultural relativity, performative enactments, discursive flexibility, and the inscrutable power of language. I use the figure of a swinging pendulum to illustrate this antagonism because - as anyone who has ever observed an old clock or a metronome knows - a pendulum swing only admits movement to extreme positions; an equilibrated middle position is only possible once the pendulum has come to a standstill - the clock's measurement of time ends, the tone dies away. The rhythm of antagonism, particularly evident in (but by no means limited to) feminist studies, is nourished by extreme positions, that is, nature or nurture, biology or culture, immutability or change.

It is against this tense background that the extraordinary appeal of Karen Barad's thinking becomes understandable. She does not accept the traditional antagonisms or fractured oppositions of the past. Instead she proposes "a sense of connectivity through the traces of variously entangled threads and of the (re)workings of mutual constitution and unending iterative reconfigurings" (Barad 2010: 245). ${ }^{1}$ She is an exquisitely well-cultured theoretical physicist who writes with the beautiful ease of a skilled novelist in combination with the uncompromising verve of a pragmatic scientist, and is thus able to conjure up tasty entanglements of quantum physics, theatre, poems, philosophy, politics, and feminism. Her knowledge appears boundless, and the limits of her explanatory scope can only be probed by the heights of her vertiginous aim, namely, to introduce nothing less than a "lively new ontology", in which: 
[T] he world's radical aliveness comes to light in an entirely nontraditional way that reworks the nature of both relationality and aliveness (vitality, dynamism, agency). This shift in ontology also entails a reconceptualization of other core philosophical concepts such as space, time, matter, dynamics, agency, structure, subjectivity, objectivity, knowing, intentionality, discursivity, performativity, entanglement, and ethical engagement (33).

Barad's work is dedicated to the development of the new ontology, or rather an "ethico-onto-epistem-ology", in which ethics, ontology, and epistemology are no longer separate fields of study (89-90, 381). And although her theory is first and foremost meant to be a contribution to "science studies, feminist studies, and other (inter)disciplinary studies" (25), Barad repeatedly credits it as a panacea for all the ailments caused by "idealist or magical" beliefs in the "representationalist" dualism of biology and culture, subjectivity and objectivity, mind and body (e.g. 5, 23-5, 55, 70, $93,131,183,221-2,317-8,391-4)$. Contrary to the reflective method with which we have long tried to understand the world and other people as discrete objects in opposition to ourselves as experiencing subjects, Barad operates with a transdisciplinary diffractive methodology by means of which the reflective distance between the experienced object and the experiencing subject is eliminated and object and subject become part of the same material enactment. Once we learn to put aside our (all too) human tendency to consider ourselves as individuals with our "own roster of nonrelational properties" who live in a world of interacting "individual entities with separately determinate properties" (55), we shall be able to see only intra-acting, entangled material phenomena without fixed boundaries, structures or identities, which are ever changing, shifting, and re(con)figuring into new phenomena. Barad calls this entirely new view of nature "agential real- ism", which, among other things, is "a posthumanist account of performativity that challenges the positioning of materiality as either a given or a mere effect of human agency. On an agential realist account, materiality is an active factor in processes of materialization"; or in the straightforward manner characteristic of her style, "matter is not a fixed essence; rather, matter is substance in its intra-active becoming - not a thing but a doing, a congealing of agency" (183-84).

She draws the main support for her argument from the enchanting subatomic world of quantum physics, which leaves most readers breathlessly behind in comprehension, but if one is to put a plump finger on her delicate theory in order to point out her principal aim, I would say that it can be boiled down to the ambition of dissolving solid differences and entrenched distinctions in order to enhance the "possibilities of change" (35).

This is surely not a new ambition in feminist thinking, and it is an attitude toward which I am quite sympathetic. We do indeed need to overcome stale prejudices, ossified habits of thinking, and not least the harmful trajectory of ideological preconceptions about (human) nature. What is new is Barads background as a physicist, and her methodological stance that can be summed up in her own slogan "Language has been granted too much power" (132). Contrary to the concern with the subtleties of language and the general suspicion about science that characterized much feminist thinking in the second half of the twentieth century, Barad uses the most profound - some would say, also the most obscure - branch of the natural sciences, quantum physics, to establish a materialism that overcomes the opposition of nature and culture at the heart of contemporary feminism. If we return to the metaphor of the pendulum swing of antagonism described above, Barad's material feminism can be read as an ambitious attempt to en- 
compass both extremes of the pendulum swing, nature as well as culture, without forcing the pendulum to what she considers to be the futile standstill of a reflective middle position. The diffractive entanglement of her lively quantum materialism ensures that everything is culture and everything is nature, and her posthumanist conviction allows her to discard traditional philosophical discussions about subjectivity, body, and individuality as unhappy byproducts of an inadequate understanding of nature. Once we adopt her "ethico-ontoepistem-ology", we are finally enabled to understand - as she writes on the final page of her long book - that:

A delicate tissue of ethicality runs through the marrow of being. There is no getting away from ethics - mattering is an integral part of the ontology of the world in its dynamic presencing. Not even a moment exists on its own. "This" and "that," "here" and "now," don't preexist what happens but come alive with each meeting. The world and its possibilities for becoming are remade with each moment. If we hold on to the belief that the world is made of individual entities, it is hard to see how even our best, most well-intentioned calculations for right action can avoid tearing holes in the delicate tissue structure of entanglements that the lifeblood of the world runs through. Intra-acting responsibly as part of the world means taking account of the entangled phenomena that are intrinsic to the world's vitality and being responsive to the possibilities that might help us and it flourish (396).

In what follows, I will try to articulate some of my concerns regarding this attempt to conflate ethics, ontology, and epistemology. Different kinds of questions are at work in each of these fields of inquiry, and I shall use Princess Elisabeth's concerns about the fragile relation of the mind and the body to articulate my main point, namely, that - in spite of Barad's methodological conflation - various questions about subjectivity, the body, and individuality still matter to contemporary feminism. I shall start with the complex epistemology involved in the subjective experience of sadness. The next section will deal with the consequences that this complexity has for our study of the ontology of the human body. The last two sections then conclude with some brief ethical considerations of the importance of subjectivity and body in relation to how feminism conceives the individual.

\section{The Subjectivity of SAd(Ness) MATTERS}

In the spring of 1645, Descartes was informed that Elisabeth had suffered from a recurrent physical malaise, characterized by "a low-grade fever, accompanied by a dry cough", which he perceptively diagnoses to be "sadness [tristesse]" (Shapiro 2007: 86 [95-6]). Elisabeth was well aware that her physical symptoms were caused by the troubles of her mind. She had been cautious about admitting this to the doctors who examined her, and she confesses that '[e]ven if they had been smart enough to suspect the part that my mind plays in the disorder of the body, I would not have the frankness to admit it to them at all" (Shapiro 2007: 88 [98]).

Elisabeth's disturbing sadness is interesting because it allows us to see why ethics, ontology, and epistemology are not as easily conflated as is the case in Barad's "ethico-onto-epistem-ology".

Despite the fact that a metaphysical dualism of mind and body may be a thing of the past, and the embodied mind has become an almost undisputed philosophical as well as scientific assumption, most people can recognize Elisabeth's puzzlement concerning the relation of the mind and the body. Most of us readily accept that ontologically speaking - our mind is our brain. The problem is, though, that this 
ontological certainty does not help us to cope with the phenomenological fact that we somehow feel that there is more to our mind than the grey matter of our brain. Although some biologically oriented psychiatrists might try to assure us that the devastating sadness accompanying severe depression is the result of imbalances in the neurobiological underpinnings of our conscious mind, such explanations seem somehow unsuitable for solving the experiential problem of sadness. I may accept that sadness is caused by the biological functions of my brain, but this acceptance does not alter the phenomenological fact that my most personal concerns (thoughts about the past and the future, jealousy, low self-esteem, economical insecurity, and so on) are somehow critical to the specific kind of sadness that $I$ feel.

Thus, even though a neurobiological explanation of sadness may be ontologically true, this does not help us very much when it comes to the epistemological subtleties of our subjective experience of sadness. In fact, subjectivity makes ontology, that is, the question of what is really real, highly problematic. What is the accurate description of sadness? Is it the careful description of complex neuromodulators (the breakdown or reuptake inhibition of monoamine transmitters such as serotonin, dopamine, histamine, etc.), or the just as careful description of the experiential features of sadness (weary thoughts, heavy body, irritable mood, lack of appetite, etc.)? This is still an intensely debated question in psychiatry, which shows that the embodied mind remains just as much a problem as it is a fact. Explanations of the mind and the brain are still two different enterprises. And this is why subjectivity matters. I am sad and you are sad, and while we both know what the other means by sadness, our respective experiences of sadness may be entirely different.

The phenomenology of sadness is particularly complex because there are some fea- tures of what we call sadness that appear to be rooted in more or less universal biological functions, while there are other features which change from culture to culture, and again features which are different from person to person. This complexity makes it necessary to operate with distinct explanatory layers when we approach such a fragile phenomenon as human sadness. Epistemological, ontological, and ethical investigations of sadness (and of most other human emotions and thoughts) are separate matters, and any attempt to conflate the various methodologies of such investigations risks losing sight of what is really at stake namely, to understand and cope with sadness. If our epistemological approach to sadness (how do we experience sadness?) is too intimately entangled with an ontological (what is sadness?) and an ethical (how should we behave when we are sad?), we very easily end up with an explanation that is both reductive (sadness is just a malfunctioning of your brain) and normatively biased (the way you behave when you are sad is inappropriate or simply wrong).

Elisabeth's reluctance about admitting to her doctors the role that her sad thoughts play in her bodily illness is an example of delicate issues involved in explanations of human problems. Every problem is always an entangled product of epistemology, ontology, and ethics to begin with. The doctors' understanding of Elisabeth's illness, their diagnosis, and their advice were undoubtedly informed and shaped by their seventeenth-century Western beliefs about physical nature, medical practice, the human body, the soul, and not least the inferior nature of women. More than three hundred years have passed, and doctors, scientists, and politicians are still confronted with entangled human problems that are all too often investigated and handled in reductive and normatively biased ways that do additional harm to - and sometimes even destroy - the suffering person involved. I would venture the claim that our 
best chance of investigating and coping with human problems is to disentangle the different methodological layers at work in our fragile conception of what it means to be human. Barad's recourse to the lively "ethico-onto-epistem-ology" of quantum physics, and the conflated methodological approach of agential realism, points explicitly in the opposite direction. Her insistence on the inescapable entanglement of phenomena engrained in the lively intra-actions of quantum physics might be a impressive (meta)physical theory about matter, but it is no help against the more concrete and serious problems of Elisabeth or those of any other human being, for that matter.

To further support this rather harsh claim I suggest that we look at how the persistence of subjectivity complicates our conception of the human body - and of the problems involved in the matter of our bodies.

\section{The Ambivalence of BODILY MATTER(s)}

Later in the letter to Descartes, quoted at the beginning of the previous section, Elisabeth expresses her gratitude to Descartes because he intends, as she writes, "to cure my body with my soul" (Shapiro 2007: 89 [99]). Some paragraphs earlier, though, she had emphasized the difficulty of such a cognitive therapy - in particular in view of the fact that she is a woman:

Know thus that I have a body imbued with a large part of the weaknesses of my sex [ des faiblesses de mon sexe], so that it is affected very easily by the afflictions of the soul and has none of the strength to bring itself back into line, as it is of a temperament subject to obstructions (Shapiro 2007: 88 [98]).

Although Lisa Shapiro, who has studied the correspondence carefully, detects a hint of irony in Elisabeth's statement, she never- theless encourages us to take seriously "her internalization of a kind of sexist attitude" (Shapiro 1999: 511). Whether she is ironic or not, Elisabeth's comments reveal not only the prejudices about the female mind and body in the seventeenth century, but also a problematic feature of bodily experience that is still very much alive today.

Once again, despite Barad's rather harsh rejection of phenomena conceived as objects "in the Kantian or phenomenological sense" (128), phenomenology can be helpful to articulate a basic problem of human embodiment, particularly if we add a whiff of what she rejects as the untenable "Kantian noumena-phenomena distinction" (33, 128, 375).

Traditionally, phenomenology operates with a basic distinction in our understanding of human embodiment: the subjective, unthematized, living body (Leib) and the objective, thematized body (Körper). This distinction is used as a way to articulate the complexity involved in the experience of the body as, on the one hand, the pre-reflective organ through which I interact with the world, i.e., the body as mine, and the body as an object on a par with other objects in the world, i.e., subjected to the anonymous laws of physics and biology (Zahavi 1999: 91-109). In other words, my experience of my body is highly ambivalent: it is mine in the most intimate sense of the word, and still it is also the intimidating object for alienating diseases and ultimately death. My body is in this sense both a phenomenon and a noumenon (here understood in the firm Kantian sense as that which lies beyond the reach of my possible experience and thus my understanding).

This ambivalent character of human embodiment is once again an expression of the abstruse relation between the mind and the body, and the ambivalence has important consequences for how a person lives with her or his body. My body is an inescapable part of who I am, but just as Elisabeth 
(ironically) complains about the gendered 'weaknesses' of her body, many people suffer under the rather unexplainable, contingent, and sometimes alienating character of their particular bodies. This bodily unease varies from rather superficial aesthetic concerns over deeply frustrating feelings about personal identity to terrible illnesses. Some feel that they are too short, others that they are too tall, some that their nose is too prominent, others suffer under premature baldness, cystic acne, underdeveloped sexual organs, overdeveloped ears, and so forth. Tragically, there are persons who are born with a body that is genetically determined to develop agonizing and terminal illnesses, and no less painfully tragic is the fate of those innumerable children who are born in regions of the world where early malnutrition and environmental pollution are the order of the day and severely inhibit - and often irreversibly destroy - the development of vital bodily organs. Why is this cruel contingency attached to our embodied existence? No matter how hard we think about our body, and often because it is in grievous opposition to our best or most intimate intentions, the nature of the human body and the contingent place in the world where this body was born remain noumena in the unmistakably Kantian sense, that is, unfathomable questions.

I shall conclude with a brief consideration of a related bodily problem of relevance to contemporary gender studies. It is an issue that involves epistemological, ontological, and ethical considerations, but also a highly delicate issue that necessitates a methodological separation of these different considerations.

\section{(THE) INDIVIdUal MATTERS}

Why does all this matter to contemporary feminism, and to the use that it makes of Barad's thinking? Once again we may take our lead from Princess Elisabeth. To cure Elisabeth's suffering body with her soul,
Descartes recommends the reading of the Stoic philosopher Seneca, who taught that all evils can be overcome and true happiness be gained if only we follow the serene path of rational thinking. We have already seen that Elisabeth is quite sceptic about such a cognitive therapy. And some months later, in August 1645, when she has eventually read the recommended work by Seneca, she restates her scepticism: "I do not yet know how to rid myself of the doubt that one can arrive at the true happiness [la béatitude] of which you speak without the assistance of that which does not depend absolutely on the will" (Shapiro 2007: 100 [114]).

Barad's theory of intra-active entanglements is crowned with a sketch of "an ethics of mattering" (391-6) that reworks central Lévinasian themes of the absolute Other. She uses these themes to argue against the metaphysics of individualism and for the idea that " $[\mathrm{t}]$ here are no singular causes. And there are no individual agents of change", which means that " $[\mathrm{r}]$ esponsibility entails an ongoing responsiveness to the entanglements of self and other" (394). Although I completely agree with the last part, which I consider to be the most admirable feature of Barad's theory, I remain very sceptic about the way she wants to arrive at this responsible entanglement of self and other. Like Elisabeth, I am concerned with the significance of contingency. In spite of the alleged quantum 'fact' that we are all (humans as well as other than human) entangled by the "delicate tissue of ethicality" that "runs through the marrow of being" (396), the subtle profoundness of this 'fact' of ethicality is not of much help when faced with the contingency often tragically at work in our embodied existence.

Ethics matters exactly because of the contingency involved in our individuality. I am who I am with all the particular and contingent features of my individual nature. I may want to be a different individual, but 
I am to a large degree stuck with this specific kind of individuality (I was born in Denmark, I am a man, I embody certain physical characteristics, a particular temperament and certain desires, feelings, beliefs, and ideas). And as Elisabeth writes, my true happiness seems to be beyond the sway of my will, and deeply entangled with these contingent features of my individuality, and with how my individual subjectivity is entangled with the individuality of the other person. In order to find an ethical path that secures the possibility of a more just and less tragic entanglement of individual persons, we need to acknowledge the ethical significance of irreplaceable persons with different characters, dreams, and desires who think and feel themselves as individuals. Among the contingent, but also persistent, features of our individual subjectivity are our feelings of sexuality and gender.

I do not think that an ethics that wishes to deal with the concrete personal, societal, and political problems of our sexuality and gender should work to dissolve individuality into delicate quantum intra-actions at "the marrow of being" or conflate nature and culture to enhance an amorphous possibility of change. On the contrary, a concrete ethics of gender should approach the problems at the rough surface of the entangled existence of individual beings. To understand how to deal with problems of gender and sexuality, this ethics starts from an investigation of why culture and nature impose different limits on our understanding and agency, why the relation of mind and body is so fragile, why subjectivity matters, why our body matters, and finally why disagreements, prejudices, condemnations, and political distortions still debar the possibility of responsible interaction and mutual acceptance from the intra-acting entanglement of our hearts. In other words, a gender-sensitive ethics should be an ethics of disentanglement that works towards solving the problems involved in the entanglement of different matter(s).

\section{CONCLUSION}

By way of conclusion, I will try to make my reservations concerning the use of Barad's methodology in gender studies more concrete by returning to the phenomenon of sadness. Earlier I insisted upon the subjective character of sadness, and on how the subjectivity of sadness entails biological and ethical implications, which risk subsiding into the entangled background of Barad's account. To understand the phenomenological, biological, and ethical dimensions of the disruptive sadness provoked by one's sexuality or gender such as, for instance, gender dysphoria, it is necessary, I would argue, that we examine those dimensions separately. As central parts of the mental illness diagnosed as gender identity disorders, these three dimensions of gender dysphoria have been clinically described as 'strong and persistent feelings of discomfort with one's assigned sex [phenomenological], the desire to possess the body of the other sex [biological], and the desire to be regarded by others as a member of the other sex [ethical]' (American Psychiatric Association 2000: 535). Although I am sceptical about the scientific and ethical validity of psychiatric diagnoses concerning sexuality and gender, I do not think that we can ignore these dimensions of the concrete despair that many people feel about their sexuality and gender. The complexity of a person's suffering from gender dysphoria renders biological taxonomies and societal concepts, norms, and conventions about sexuality and gender highly instable. I am a man who feels that I am a woman. Those feelings are further complicated by the experiential fact that my gender and my sexuality sometimes come apart in the fragile texture of my emotional life, and challenge biological and societal paradigms of 'normality'. Biologically I am a heterosexual male who feels attracted to women, but personally I am a homosexual female who longs to be desired, recognized, and accepted as the person that I am. My identity as an individ- 
ual person is what is at stake in my sexual and gendered feelings. Despairing about my gender includes, among other things, ambivalent feelings about the concrete subjective, biological, and normative difficulties that I experience in my possibility of challenging my own and other people's conceptions of 'normality'. An approach to the suffering involved in gender dysphoria therefore needs to recognize that we are dealing with an ambivalent, albeit painfully concrete, phenomenon with at least three distinct levels, each of which requires its own methodological approach: the phenomenological structures of how gender and sexuality affect my experience of the world, other people, and myself (e.g. Heinämaa 2003); the biological functions of sexuality and gender (e.g. Hines 2004); and the ethical aspect of being a gendered and sexual person (e.g. Irigaray 1984). Only by such a disentangled approach can we hope to shed light on the experiential ambivalence of our gendered and sexual sufferings, understand the role biology plays in this ambivalence, and face the normative challenges involved in our work towards formulating an ethics that no longer neglects the existential fragility of those who are most in need of understanding and recognition.

Throughout this article I have insisted on the individual because I believe that the concrete problems of the individual person should always be at the centre of the variegated epistemological and ontological approaches involved in an interdisciplinary research field such as gender studies. All too often the individual person has been lost from sight in the century-long battle of nature versus nurture, biology versus culture. What I admire and applaud in Barad's thinking is, in fact, her serious attempt to establish a methodological foundation that may attenuate the entrenched antagonism between cultural and biological perspectives, which continues to bedevil our endeavour to understand gender and sexuali- ty. As such her work is an important contribution to the growing awareness of the need to reconceptualize the conflictual relation of biology and culture in our conception of human gender and sexuality. I remain sceptical, however, about the conflation of ontology, epistemology, and ethics at the heart of her agential realism. The sheer scope of her "ethico-onto-epistem-ological" proposal, together with her harsh dismissal of what she considers to be anthropocentric prejudices of traditional philosophy, makes her project insensitive both to valuable insights from the tradition that she seeks to overturn and to the concrete ethical, ontological, and epistemological problems of individual persons who live with the (diffractive) effects of that tradition. Solid scientific theories (from natural science to cultural anthropology) are rarely, if ever, wholesale rejections of what went before; rather, they are the product of patient endeavours to improve on what is right or beneficial and mend what is wrong or damaging in the tradition out of which they grew.

My initial concern that feminist theorists should be careful when adopting Barad's materialist account is therefore part of my general worry regarding the scope and apersonal character of Barad's approach. So I believe that while contemporary feminism can only benefit from Barad's attempt to rethink the antagonism between biology and culture, feminist theorists should nevertheless be suspicious about her methodological proposal to conflate the ontological, ethical, and epistemological aspects of the interdisciplinary field of gender studies of which their theories are a part.

\section{Notes}

1. If nothing else is indicated, all page references in the text to Karen Barad are to (Barad 2007). 


\section{LITERATURE}

- American Psychiatric Association (2000): Diagnostic and Statistical Manual of Mental Disorders, $4^{\text {th }}$ edn, text revised. American Psychiatric Association, Washington DC.

- Barad, Karen (2007): Meeting the Universe Halfway: Quantum Physics and Entanglement of Matter and Meaning. Duke University Press, Durham, NC.

- Barad, Karen (2010): Quantum Entanglement and Hauntological Relations, in: Derrida Today, $2010 / 3$.

- Heinämaa, Sara. (2003): Toward a Phenomenology of Sexual Difference: Husserl, Merleau-Ponty, Beauvoir. Rowman \& Littlefield Publishers, Lanham, MD.

- Hines, Melissa (2004): Brain Gender. Oxford University Press, Oxford.

- Irigaray, Luce (1984): Éthique de la différence sexuelle. Les éditions de minuit, Paris.

- Kitcher, Philip (1993): The Advancement of Science: Science Without Legend, Objectivity Without Illusions. Oxford University Press, Oxford.

- Shapiro, Lisa (1999): Princess Elisabeth and Descartes: The Union of Soul and Body and the Practice of Philosophy, in: British Journal for the History of Philosophy, 1999/3.

- Shapiro, Lisa (ed.) (2007): The Correspondence between Princess Elisabeth of Bohemia and René Descartes. Chicago University Press, Chicago, IL/Descartes, René: Correspondance avec Elisa- beth, ed. Jean-Marie Beyssade \& Michelle Beyssade. Garnier-Flammarion, Paris. - Zahavi, Dan (1999): Self-Awareness and Alterity: A Phenomenological Investigation. Northwestern University Press, Evanston, IL.

\section{SUMMARY}

Different Kinds of Matter(s) - Subjectivity, Body, and Ethics in Barad's Materialism This article questions the methodological conflation at work in Karen Barad's agential realism. Barad's immense appeal is first explained against the tense background of the nature/culture antagonism in the twentieth century. Then, by using some of the penetrating observations of a seventeen-century philosopher, Princess Elisabeth of Bohemia, Barad's "ethico-onto-epistem-ology" is examined and subsequently criticized for disregarding the persistence of subjectivity, dissolving the ambivalence of the bodily matter(s), and neglecting the need for concrete individuality in ethics.

René Rosfort, PostDoc at the Faculty of Theology University of Copenhagen 